\title{
SOBRE EL OBJETO Y EL MÉTODO DE LA HISTORIA CONSTITUCIONAL ESPAÑOLA ${ }^{1}$
}

\author{
IGNACIO FERNÁNDEZ SARASOLA \\ Profesor Titular de Derecho Constitucional \\ Universidad de Oviedo
}

\author{
SUMARIO \\ I. Alguna precisión sobre el objeto de la \\ historia constitucional \\ II. ¿Qué puede aportar el constitucionalista a \\ la historia constitucional? \\ III. ¿Qué puede aportar la historia constitu- \\ cional al constitucionalista?
}

\begin{abstract}
Si estamos realmente capacitados para aprovechar las enseñanzas que la Historia encierra en sus páginas, muchas y muy fecundas lecciones encontraremos en el estudio de las causas que determinaron la frecuencia de los cambios de las Constituciones; en el examen de las apasionadas discusiones a que dieron lugar, y en la apreciación de las consecuencias engendradas por la aplicación de los preceptos contenidos en cada una de aquéllas" (Jerónimo Bécker, La reforma constitucional en España-1923-)
\end{abstract}

\section{ALGUNA PRECISIÓN SOBRE EL OBJETO DE LA HISTORIA CONSTITUCIONAL}

La Historia Constitucional española goza de buena salud, tanto en términos académicos (no hay programa de Derecho Constitucional que omita referencias

1 Este artículo ha sido redactado a raíz de la conferencia impartida en la Jornada sobre orientación y método del Derecho Constitucional, organizada por la UNED el día 16 de noviembre de 2007, en la Comisión Aspectos históricos, metajurídicos y de derecho comparado.

En virtud del Convenio de cooperación suscrito entre Teoría y Realidad Constitucional y la Revista General de Derecho Constitucional este trabajo se publica conjuntamente en ambas revistas. 
a esta disciplina $)^{2}$ como científicos, con la proliferación de publicaciones e iniciativas intelectuales de muy diverso signo. Por añadidura, el próximo bicentenario de los orígenes de nuestro constitucionalismo a buen seguro que servirá como acicate para que la Historia Constitucional reciba un nuevo impulso. Pero aun antes de que se llegue a tales fastos, ya existen claros indicios de que nuestro país se está convirtiendo en un referente para la Historia Constitucional: baste mencionar que aquí ha surgido la primera revista sobre esta disciplina en el mundo - y actualmente la única en formato digital—, así como la primera biblioteca virtual de Europa centrada en dicha materia ${ }^{3}$.

Sin embargo, todas estas iniciativas no se han visto acompañadas de reflexiones metodológicas sobre la Historia Constitucional ${ }^{4}$. Una carencia que deriva de una doble circunstancia: por una parte, porque no representa a día de hoy una disciplina académica autónoma, lo cual dificulta la proliferación de propuestas metodológicas ligadas a la docencia; por otra, porque una de las virtudes de la Historia Constitucional, cual es su carácter multidisciplinar, obstaculiza la formación de un método de trabajo común en el que puedan ponerse de acuerdo las distintas ramas del saber implicadas.

A pesar de ello, la Historia Constitucional posee autonomía respecto de otros sectores de conocimiento, ya que está dotada de un objeto de estudio

2 Prácticamente en todos los programas de la asignatura de Derecho Constitucional impartidos en las Facultades de Derecho, se dedica alguna lección a la historia constitucional española. Mayor peso tiene en algunos programas, como el del prof. J.A. GonZÁLEz-ArEs Fernández, en la Facultad de Derecho de Ourense, en el que el mayor número de lecciones de la asignatura troncal "Derecho Constitucional I" está dedicado a la historia. Al margen de esta situación, conviene destacar que también están proliferando asignaturas optativas sobre historia constitucional (ya sea española o comparada). Así, por ejemplo, sin ánimo de exhaustividad, pueden referirse las siguientes: "Historia del constitucionalismo" (impartida por J. VArela Suanzes-Carpegna en la Facultad de Derecho de la Universidad de Oviedo); "Introducción a la Historia del Constitucionalismo Español" (impartida por J.M. SÁNCHEz Estévez en la Universidad de Salamanca, Facultad de Educación). "Historia del constitucionalismo" (impartida por C. Álvarez Alonso en la Facultad de Derecho de la Universidad Autónoma de Madrid); y "Constitucionalismo histórico español” (impartida por María del Carmen Sáenz Berceo en la Facultad de Derecho de la Universidad de la Rioja).

3 Ambas bajo la dirección del más cualificado investigador de Historia Constitucional en España, Joaquín Varela Suanzes-Carpegna. La revista electrónica "Historia Constitucional" (http://hc.rediris.es), de difusión libre y periodicidad anual, es coeditada por el CEPC y la Universidad de Oviedo, y ya ha visto publicados ocho números. Por su parte, la Biblioteca Virtual de Historia Constitucional "Francisco Martínez Marina" (http://www.bibliotecadehistoriaconstitucional.com), financiada por las mismas instituciones, lleva operando desde el mes de mayo de 2007 y cuenta con más de un centenar de obras de libre consulta.

4 El único estudio hasta ahora realizado en nuestro país es el brillante texto de VARELA SUANZES-CARPEGNA, J., "Algunas reflexiones metodológicas sobre la historia constitucional", en Historia Constitucional, 8 (2007) (http://hc.rediris.es/08/index.html), incluido también en este mismo número de Teoría y Realidad Constitucional. El texto fue previamente publicado en francés, en el número 68 de la "Revue Française de Droit Constitutionnel", octubre de 2006. También en 2006 se publicó, esta vez en italiano, en el número 12 del Giornale di Storia Costituzionale. La preocupación del profesor Varela sobre las metodología de la historia constitucional — disciplina en la que es el auténtico referente en nuestro país- también se ha materializado en sendas entrevistas a los profesores BöCKENFÖRDE y TROPER, realizadas en la revista que dirige, "Historia Constitucional" (números 5 y 7 , respectivamente), y en las que se abordan interesantes cuestiones de método. 
propio y específico que lo diferencia del Derecho Constitucional, la historia de las instituciones o la historia política, con las que guarda una relación estrecha sin llegar a confundirse. Desde mi punto de vista (y aun tratándose de un asunto controvertido), ese particular objeto de estudio comprendería por igual la historia de las Constituciones y la historia del constitucionalismo. Y el método de análisis más adecuado para abordarlo sería, precisamente, aquel en el que ambos elementos se examinasen conjuntamente, sin escindirlos o tratarlos aislados entre sí.

En efecto, la Historia Constitucional se ocupa de las Constituciones de antaño ${ }^{5}$. El primer problema evidente que ha de afrontarse consiste en dilucidar qué se ha de entender por "Constitución" en esta disciplina. Resulta obvio que no puede emplearse una idea exclusivamente formal de Constitución (como norma caracterizada por la supremacía formal en el ordenamiento, al margen de su contenido) por dos circunstancias: por una parte, porque el concepto de Constitución que se maneje debe guardar una relación estrecha - casi de ósmosis - con la idea de constitucionalismo que, obviamente, no siempre ha concebido la Constitución como norma dotada de supremacía jurídica; por otra, porque siendo una disciplina histórica, ha de tener presente no ya el significado actual del concepto de Constitución, sino el que adquirió desde sus primeros momentos, tratando de analizar los distintos sentidos que se le han otorgado.

Por estas razones, creo el concepto de Constitución al que se refiere la Historia Constitucional debería ser necesariamente amplio. Habría de comprender, obviamente, la Constitución formal (Constitución como norma jurídica suprema), pero también la Constitución en sentido material, entendiendo por ésta no ya las instituciones y fuerzas políticas imperantes en cada momento — según la definición que realizara Costantino Mortati- sino los textos constitucionales definidos por su contenido, por la materia de que se ocupan, y no por su posición en el ordenamiento ${ }^{6}$. Cuál sea ese contenido que define las Constituciones es algo que debe ponerse en relación con el otro objeto de estudio, a saber, el constitucionalismo. Pero, como señalaré en breve, desde mi punto de vista éste no puede identificarse sólo con el liberal, por lo que es preciso utilizar un concepto de Constitución más extenso que el definido por el tantas veces citado artículo 16 de la Declaración de Derechos del Hombre y del Ciudadano de 1789. En efecto, no sólo debe considerarse como Constitución (en sentido material) aquella que regule los clásicos derechos civiles y establezca una separación de poderes ${ }^{7}$. Lo es también aquel texto normativo que organice jurídica-

5 También podría incluirse el estudio de la formación y desarrollo histórico de Constituciones todavía vigentes. Esto es evidente para textos tan longevos como el norteamericano, pero también lo es para cualquier otra Constitución. En España, el proceso constituyente de 1978 o la formación del Estado de las Autonomías formarían parte también de la Historia Constitucional "de las Constituciones vigentes".

6 Vid. por todos de Отто, I. Derecho Constitucional. Sistema de fuentes, Ariel, Barcelona, 1988, págs. 17 y ss.

7 El problema de la definición constitucional en los términos del art. 16 de la Declaración de Derechos estriba en concretar qué derechos subjetivos se consideran esenciales o cuándo se en- 
mente el Estado, fijando las competencias de sus órganos superiores (parte orgánica) y, en su caso, concretando de modo expreso el modo en que esos órganos se van a relacionar con la sociedad (parte dogmática). Lo que sí ha de ser consustancial al concepto de Constitución es la idea de límite del poder público (dotado de soberanía jurídica), herencia ante todo del movimiento liberal; allí donde carezca de esta característica no podría hablarse con propiedad de norma constitucional ${ }^{8}$.

En este sentido, es preciso añadir que, debido a que la Historia Constitucional asume, entre otras, una definición material de Constitución, ha de ocuparse también de las normas "materialmente constitucionales", es decir, aquellas que regulan los órganos constitucionales y los derechos "fundamentales". Así, no pueden dejar de analizarse las leyes electorales, los reglamentos parlamentarios o las leyes y reglamentos reguladores de la Jefatura del Estado, el Gobierno o el poder judicial; del mismo modo, tampoco puede olvidarse la Historia Constitucional de las leyes que desarrollan los derechos constitucionales, tomando también muy en cuenta, por ejemplo, el Código Civil y el Código Penal, por la incidencia que tienen, respectivamente, en la regulación de la propiedad y de la libertad personal ${ }^{10}$.

tiende que existe una verdadera división de poderes. Por ejemplo, la Constitución de Bayona no reconocía de forma inmediata determinadas libertades como la de expresión o imprenta (esta última se aplicaría con posterioridad a la entrada en vigor de la Constitución), que en algunos casos han llegado a considerarse nucleares en el origen de los derechos fundamentales; o por ejemplo, el Estatuto Real, que incluso carecía de regulación de libertades. Por lo que se refiere a la división de poderes, ésta es más que discutible por ejemplo en un sistema convencional (como el de la Constitución francesa de 1793), donde la Asamblea tiende a absorber todas las funciones públicas. Tal sucedió también en España durante el gobierno de las Cortes de Cádiz que, basándose en un poder de "suprema inspección" derivado de su naturaleza constituyente, les legitimaba a adoptar decisiones gubernativas, ejecutivas e incluso jurisdiccionales.

8 Esta es la esencia común del constitucionalismo (ya sea liberal, democrático y social), por lo que donde no esté presente la idea de límite del poder estatal, no cabe hablar en propiedad de Constitución. En muchos de los sistemas dictatoriales, así como en gran parte de los regímenes de partido único, esta pretensión limitadora no existe. No obstante, es obvio de la división de poderes y los derechos civiles subjetivos conforman, como percibió el liberalismo, dos de los medios más eficaces para limitar al Estado al circunscribir un campo de acción positiva (poderes y funciones estatales) y negativa (libertades públicas). Sin embargo, otras visiones constitucionales distinta de la liberal también pueden implicar limitaciones del poder Estatal: así, en el constitucionalismo democrático, la necesidad de contar con la voluntad de las minorías, la participación política con un sufragio universal, los mecanismos de democracia directa o el reconocimiento del cuerpo electoral como órgano del Estado; en el constitucionalismo social, el ejemplo más evidente sería la concepción prestacional de las libertades, convirtiendo en derecho subjetivo la obligación del Estado de proporcionar determinados bienes o servicios.

9 Por supuesto que la "fundamentalidad" de los derechos ha de estar en relación con el concepto mismo de Constitución. Dicho en otros términos: para la Historia Constitucional, los derechos son "fundamentales" por su inclusión en el texto constitucional y, por ende, por su especial valor político para el Estado, que los ha seleccionado en un momento histórico concreto como el estatuto jurídico básico de los sujetos.

10 A diferencia de lo que sucedería hoy en día, en el que un Código no puede servir para interpretar el contenido constitucional, por la subordinación jerárquica de aquél, la situación es muy distinta en la Historia Constitucional. Código y Constitución pueden responder a una misma 
Ya se ha dicho que la historia del constitucionalismo también forma parte integrante de la Historia Constitucional. En este caso, se trata de estudiar el fenómeno doctrinal que, surgido desde el siglo xviI, trató de establecer límites al Estado soberano con el objeto de garantizar las libertades subjetivas. Sin embargo, y a igual que el concepto de Constitución ha variado con el tiempo, el estudioso debe tener presente que también el constitucionalismo ha ido evolucionando, hasta el punto de que se puede hablar de un constitucionalismo liberal, otro democrático y otro social, y todos ellos han de ser por igual contemplados por la Historia Constitucional. Dicho en otros términos: el constitucionalismo nace con una determinada lectura de las relaciones sociedad-Estado (separación) que luego se va modulando (participación de la sociedad en el Estado y, posteriormente, prestación del Estado a la sociedad) y todos estos modelos deben disponer de su espacio en los estudios histórico-constitucionales. Esos distintos paradigmas de constitucionalismo inciden, como ya se ha dicho, en el concepto material de Constitución, y por ese motivo, la Historia Constitucional no sólo debe atender a las Constituciones liberales (que reconocen derechos individuales y separación de poderes) sino también a las democráticas y sociales, donde pueden faltar algunas de las anteriores premisas, aunque no la pretensión limitadora del poder inherente al constitucionalismo.

Precisamente porque este último es también objeto de estudio, cabría hablar de una Historia Constitucional sin Constitución o, al menos, sin Constitución en sentido formal, que se centre en la doctrina del constitucionalismo. Pero entonces emerge un nuevo problema: ya que la idea de límite al ejercicio del poder ha sido una constante desde el pensamiento clásico, ¿no debe ocuparse la Historia Constitucional también del que se ha venido en denominar como "constitucionalismo antiguo", es decir, las teorías y normas greco-romanas y medievales forjadas con la intención de limitar el poder público? En relación con este complejo y controvertido asunto, estimo que en realidad el "constitucionalismo antiguo", al que McIlwain dedicara su universal obra ${ }^{11}$, debe considerarse más como un precedente que como el verdadero objeto de la Historia Constitucional. Y ello porque ésta debería tener como presupuesto la existencia

dogmática, y los términos en el que el primero está redactado (siempre más concretos que los artículos constitucionales) pueden servir para obtener un significado preciso de la segunda. Ahora bien, se pueden obtener resultados equívocos si se prescinde de la base doctrinal que subyace al Código. Así ha sucedido, por ejemplo, cuando algunos historiadores del Derecho (basándose exclusivamente en un enfoque institucional, y prescindiendo de la doctrina) han interpretado la Constitución de 1812 a partir del proyecto de Código Civil de 1821, sin tener presente que los diez años que median entre ambos textos habían supuesto un cambio doctrinal y, de hecho, el citado proyecto responde fundamentalmente al pensamiento liberal moderado, que se hallaba ausente en el proceso de elaboración de la Constitución de Cádiz.

11 Howard Mc IlwaIn, Ch., Constitutionalism Ancient and Modern, Cornell University, Ithaca-New York, 1940. 
de un Estado soberano, cuya relación con la sociedad es precisamente lo que tratan de articular tanto la Constitución como el constitucionalismo ${ }^{12}$.

Antes de la formación de un Estado soberano existían elementos extraconstitucionales que servían como limitación efectiva del poder: baste pensar en la ley divina o en las funciones y fines propios de cada grupo integrante de la comunidad estamentalmente estructurada, o la existencia de relaciones de dominación naturales. A ello habría que añadir la dispersión de poder propia de los ordenamientos jurídicos preestatales, sin un centro único de autoridad. Por el contrario, cuando el poder público se concentra en un único sujeto soberano, el Estado, es cuando nace la dicotomía clara entre éste y la sociedad, y cuando, en consecuencia, surge el auténtico dilema de cómo sujetar a un poder que por su esencia misma resulta ilimitado.

En este sentido, y aunque insisto en que el "constitucionalismo antiguo" o "preconstitucionalismo", como lo denominaba Nicolás Pérez Serrano ${ }^{13}$ — puede verse y estudiarse como un precedente, no considero que conforme un objeto de estudio propio de la Historia Constitucional y sí, acaso, de la historia del pensamiento o de la historia de las instituciones. Otro tanto puede afirmarse de lo que hoy ha venido en llamarse el "constitucionalismo indígena", referido a unas realidades preestatales a las que se añade la dificultad de tratar con culturas muy distintas a las occidentales, a veces con escasos testimonios escritos o con lenguas poco accesibles a los estudiosos actuales.

\section{II. ¿QUÉ PUEDE APORTAR EL CONSTITUCIONALISTA A LA HISTORIA CONSTITUCIONAL?}

Aunque la Historia Constitucional no sea ya un ámbito casi exclusivo del constitucionalista — que, de hecho, cada vez abandona más este campo para recluirse en el estudio del Derecho positivo-, éste puede hacer aportaciones de trascendencia. En concreto, la mayor contribución del constitucionalista reside en su conocimiento de las categorías político-constitucionales, instrumentos esenciales para diseccionar la Historia Constitucional. Qué se entienda por nación o pueblo (con sus relevantes diferencias), por soberanía, las distintas formas de gobierno, el control de constitucionalidad (en sus modalidades de abstracto o concreto)... todas estas categorías pertenecen al acervo del constitucionalista, formado en la teoría del Estado y de la Constitución. Por tal motivo, el empleo adecuado de tales conceptos marcará su impronta en los estudios de Historia Constitucional.

12 Véase a este respecto la reflexión de VARELA SuANzES-CARPEgna, J., en su recensión "Talante $y$ doctrina liberales (Comentario a libro de Leo Strauss "Liberalismo antiguo y moderno")", Revista de Libros, 2008 (en prensa).

13 Pérez Serrano, N., El Constitucionalismo europeo (Ateneo de Madrid, 1948), en Pérez SERRANo, N., Escritos de Derecho Político, Instituto de Estudios de Administración Local, Madrid, 1984, vol. I, pág. 387. 
Pero no se trata sólo de usar esos conceptos con propiedad, sino también de exportarlos a otras ramas del saber, en especial a la historia, de modo que pueda ir forjándose un lenguaje científico específico de la Historia Constitucional, común a todos los investigadores que se ocupen de esta disciplina. De este modo se solventaría un déficit conceptual existente en nuestro país, y que no se aprecia en otras latitudes. Así, por ejemplo, en Estados Unidos los historiadores utilizan y conocen bien conceptos constitucionales tales como rule of law, judicial review, cabinet system, congressional government o due process of law, por poner sólo algunos ejemplos. Falta igual comprensión conceptual en nuestro país, y ello dificulta un diálogo eficaz entre las distintas ramas del saber que se ocupan de la Historia Constitucional.

En este punto, conviene apuntar que la reticencia de algunos historiadores a emplear las categorías constitucionales no sólo responde al hecho de tratarse de conceptos que les son ajenos y con los que no se sienten implicados, sino que, además, suele aducirse también el argumento de que no pueden emplearse categorías actuales para referirse a situaciones pretéritas sin incurrir en el riesgo de descontextualización. Esta crítica resulta, sin embargo, infundada, ya que es obvio que sin categorías construidas no hay ciencia. Por otra parte, no debe confundirse la Historia Constitucional con la historia de los conceptos, sin perjuicio de que - como en breve indicaré- la primera tenga que tener muy presente la segunda. El uso de categorías constitucionales no sólo es lícito, sino necesario, aunque el constitucionalista debería advertir que los términos utilizados no se empleaban en el contexto histórico concreto $^{14}$. Después de todo, lo que a veces parece olvidarse es que todos esos conceptos que empleamos los constitucionalistas son, las más de las veces, fruto de un proceso inductivo a partir de experiencias históricas: así, por ejemplo, de resultas de las diferentes formas en que se controló la constitucionalidad de las leyes en Estados Unidos (sobre todo desde 1803 con la famosa sentencia Marbury vs. Madison), y en la Europa continental (a partir de la implantación del modelo kelseniano de Tribunal Constitucional en la Constitución austriaca de 1919), se han forjado los conceptos de jurisdicción difusa y concentrada.

Bien es cierto que, a su vez, el constitucionalista que se acerca a la Historia Constitucional debería también tener presente que ha de emplear una metodología distinta a la que utiliza cuando disecciona textos positivos. Y es que el normativismo, insoslayable en la ciencia jurídica actual, no puede resultar tan "puro" - siguiendo terminología kelseniana- cuando se trata de estudiar la Historia Constitucional. En primer lugar, uno de los errores más frecuentes en

14 A modo de ejemplo: en el Trienio Liberal las Cortes empezaron a juzgar la conducta de los ministros no sólo en términos de infracción normativa, sino también cuando resultaba inadecuada. Por tanto, es perfectamente correcto - incluso necesario para hacer ciencia- indicar que allí empezaba a emerger una idea de "responsabilidad política", aunque no fuera este el concepto que empleasen entonces los actores políticos, sino el de "responsabilidad moral". La negativa a utilizar categorías construidas es un auténtico absurdo en cualquier ciencia: un médico hablará de una enfermedad del siglo xvi con el nombre que tiene actualmente, aunque haga notar que en aquella época la enfermedad en cuestión no se conocía o, en su caso, se denominaba de forma diferente. 
los que se suele incurrir reside en interpretar las Constituciones históricas con las mismas herramientas hermenéuticas que se emplean hoy en día para diseccionar los textos positivos. Esta errónea praxis pasa por alto que los métodos interpretativos se hallan ligados al concepto mismo de Constitución al que se apliquen y que, como ya he indicado, éste no es idéntico en el Derecho Constitucional y en la Historia Constitucional. Como es de sobra conocido, la supremacía jurídico-formal de las Constituciones actuales determina la preferencia por una interpretación literal y sistemática de sus preceptos, como lógica imposición de principios como los de unidad y concordancia práctica. Pero las Constituciones a las que se refiere la Historia Constitucional no tienen por qué estar dotadas de esa supremacía, por lo que el método interpretativo actual no resulta extrapolable y, o bien resulta inadecuado, o bien ha de matizarse su empleo.

De este modo, cuando se acuda a la interpretación literal debería tenerse presente que los términos no siempre han tenido el mismo significado. Es aquí, precisamente, donde entra en juego la historia de los conceptos, que el historiador constitucional ha de conocer bien. Lo contrario sí que sería descontextualizar la interpretación que se haga del articulado constitucional: no puede determinarse el significado que tenían conceptos políticos por el rasero actual, y será preciso saber con exactitud qué sentido tenían en el momento en que se añadieron al texto normativo. En definitiva: a nadie se le ocurriría interpretar hoy la Constitución actual al margen de la jurisprudencia constitucional, del mismo modo que no es acertado interpretar los términos de Constituciones pasadas sin saber qué significaban en su contexto histórico ${ }^{15}$.

Por su parte, la interpretación sistemática propia de las Constituciones modernas debe ceder a favor de otras interpretaciones, como la auténtica o la teleológica que tienen de hecho un mayor valor. El constitucionalista no puede indagar el significado de un artículo constitucional a partir de otros artículos del entramado de la Constitución, prescindiendo del sentido que le otorgaba el constituyente, la doctrina de la época, o incluso del significado que adquirió a partir de acontecimientos políticos concretos. De ahí que no sólo haya que conocer las Constituciones, sino también lo que podríamos llamar la "cultura constitucional". En este sentido, habrá que acudir necesariamente a los diarios de sesiones, si los hubiere, a las obras doctrinales de la época y a Constituciones coetáneas influyentes. Pero al hacerlo habrá que actuar con suma cautela: no basta con consultar Constituciones y doctrina de la época, sino que será preciso también determinar si tuvieron alguna incidencia en el proceso constituyente. Por eso resulta imprescindible conocer también el "flujo constitucional", es decir, la circulación de ideas y textos normativos por los distintos

15 Tampoco sería adecuado acudir simplemente al significado que dieran los jueces en el pasado a los términos constitucionales. Y ello porque en nuestra historia los jueces nunca tuvieron el monopolio interpretativo de la Constitución, a diferencia de lo que ocurre en la actualidad. Así, en los modelos constitucionales históricos basados en el legicentrismo, es más relevante tomar en consideración la interpretación realizada por el legislador que la llevada a cabo por el poder judicial. 
países ${ }^{16}$. En definitiva, puede decirse que el riesgo más evidente que se asume al hacer Historia Constitucional es la descontextualización temporal, geográfica o conceptual, es decir, tratar el texto constitucional en abstracto, desconociendo aquellos pilares que lo tienen asido a una realidad concreta. De ahí la dificultad de esta disciplina, porque obliga a conocer la historia - política, conceptual, de las instituciones - para poder interpretar adecuadamente el articulado constitucional.

Precisamente por ello, es muy importante una depuración cuidadosa de las fuentes de estudio, acudiendo en la medida de lo posible a fuentes directas. La Historia Constitucional exige manejar archivos y consultar expedientes y legajos, algo que, huelga decirlo, no suele ser habitual entre los constitucionalistas, que no necesitan de esta prospección para sus investigaciones de Derecho positivo. Por otra parte, la dificultad se incrementa al tener que combinar fuentes de procedencia muy distinta para llegar a desentrañar el significado histórico de determinados conceptos. Por ejemplo, es posible que el sentido de un enunciado constitucional no se desprenda de los debates constituyentes, debiendo entonces acudir a la doctrina de la época, o incluso a las obras redactadas por los constituyentes. En otras ocasiones, los diarios de sesiones - que conforman una fuente primaria para la Historia Constitucional - tendrán que cotejarse con otras fuentes complementarias, debido a que pueden haber recogido de forma parcial o sesgada el contenido de las deliberaciones ${ }^{17}$. En este punto la prensa, por ejemplo, puede servir de apoyo cuando contiene resúmenes de los debates parlamentarios, o también la descripción que de las discusiones hayan realizado sus protagonistas.

\section{III. ¿QUÉ PUEDE APORTAR LA HISTORIA CONSTITUCIONAL AL CONSTITUCIONALISTA?}

"Aparece a menudo en los jóvenes colegas una tendencia hacia un "positivismo del Tribunal Constitucional". De modo que el Derecho Constitucional se convierte en la explicación e interpretación de las decisiones del Tribunal Constitucional". Estas palabras fueron recientemente pronunciadas por ErnstWolfgang Böckenförde, quien a su dilatada trayectoria como historiador del

16 Por ejemplo, no puede considerarse sin más una influencia Benthamiana porque una Constitución emplee el término «utilidad pública». Habrá que comprobar en la medida de lo posible si Bentham era conocido por los constituyentes o no. Igualmente, dos términos coincidentes en sendas constituciones de distintos países no significa que haya existido una influencia directa entre ellas. Pueden responder a una misma cultura constitucional, y eso será algo que tendrá que averiguar el investigador.

17 Vid. al respecto Lorente, L., La voz del Estado. La publicación de las normas (1810-1899), CEPC, Madrid, 2001; Los empleados de la redacción del diario de sesiones y la colección de decretos de las cortes generales y extraordinarias, Revista de Estudios Políticos, núm. 93, 1996, págs. 85-95. 
constitucionalismo, añade el haber sido magistrado del Tribunal Constitucional alemán durante trece años ${ }^{18}$.

En este razonamiento de Böckenförde creo que puede situarse la cuestión acerca del interés o importancia que el conocimiento de la historia constitucional puede suponer para el estudioso del Derecho Constitucional. Ante todo, parece preciso diferenciar al constitucionalista del mero aplicador constitucional. Para el segundo posiblemente el conocimiento de la Historia Constitucional no represente una parte esencial de su formación como jurista, aunque, como recientemente ha señalado el profesor Rubio Llorente, si entendemos la Constitución como norma integradora de una comunidad política, también el aplicador del Derecho debiera tener presente el devenir histórico, para conocer el relativismo de los conceptos constitucionales ${ }^{19}$.

Para el constitucionalista la respuesta parece en todo caso clara. La formación de éste incluye todo un elenco de conocimientos que posiblemente no tengan una utilidad inmediata, pero que contribuyen a su formación intelectual y permiten diferenciarlo del aplicador constitucional. Así, la teoría del Estado y de la Constitución, o la conceptualización de las formas de gobierno, por poner algunos ejemplos significativos, forman parte del status irrenunciable del constitucionalista. En este sentido creo que hay que interpretar las palabras del profesor Böckenförde, ya que son estos conocimientos los que, a la postre, diferencian al constitucionalista de los operadores jurídicos y los que contribuyen a que, más allá de ser exegetas del Tribunal Constitucional, puedan realizar sus propias construcciones. En todo caso, el bagaje de cultura constitucional que ha de poseer un constitucionalista no puede mensurarse por el mero parámetro de la "utilidad inmediata" a la que suelen circunscribirse aquellos que adoptan una visión mercantilista y cicatera de los conocimientos jurídicos.

En este sentido, estimo que también es preciso diferenciar quien estudia el Derecho Constitucional "de lege lata" y quien lo hace también "de lege ferenda". El primero suele ser quien se considere más desvinculado de la Historia Constitucional, pero el segundo sin duda no puede prescindir de esa disciplina. Algo que se percibe muy en especial cuando se plantea una reforma constitucional o, aun más, un proceso constituyente, ya que en esas situaciones las experiencias pasadas - sobre todo las más próximas en el tiempo- pueden servir de guía. Baste consultar el dictamen del Consejo de Estado sobre la reforma constitucional, para hallar en él numerosas referencias a la historia constitucional de nuestro país ${ }^{20}$.

18 Entrevista de J. VAREla SuAnzes-CARPEgna al profesor E.W. BöCKEnFÖRde, en Historia Constitucional (revista electrónica), núm. 5, 2004 (http://hc.rediris.es/05/Numero05.html).

19 Cfr. Rubio Llorente, F., Prólogo a Varela Suanzes-Carpegna, J., Politica y Constitución en España (1808-1978), CEPC, Madrid, 2007, págs. XIX-XX.

20 Incluso en lo referente a la denominación de las Comunidades Autónomas se incluye un epígrafe en el que los precedentes de historia constitucional se añaden a los ejemplos del Derecho comparado, para servir como ejemplo (Consejo de Estado, Informe sobre modificaciones de la Constitución española, febrero de 2006, págs. 147 y ss.). El propio Presidente del Consejo de Estado, ha puesto de relieve este recurso a la historia que se desprende del informe del supremo ór- 
La Historia Constitucional representa además un recurso indispensable cuando se analizan sistemas basados en convenciones constitucionales, como es el británico y, hasta cierto punto, el belga. Pero también cuando se parte de un sistema positivo, dotado de una Constitución formal, hay referentes históricos que no pueden soslayarse con facilidad. La teoría constitucional parte de apriorismos que, en realidad, responden a construcciones históricas. Cuando decimos que la democracia implica participación, o defensa de las minorías, "autorreferencialidad y positividad", cuando diferenciamos la democracia individualista de la orgánica o la procedimental de la material, estamos empleando categorías construidas a partir de procesos históricos, sin cuyo conocimiento es posible que no entendamos bien ${ }^{21}$. La interpretación de los artículos constitucionales sin abandonar el enunciado constitucional está abocada a manifiestas contradicciones: si nos ceñimos al mero normativismo, una Constitución que no conceda participación ciudadana y que confiera todo el poder a un sujeto tendría que considerarse democrática si ella misma se autodefine como tal. Si, por el contrario, negamos que en verdad pueda adjetivarse como democrático un texto con tal forma de estructurar el poder, es porque partimos de un concepto predefinido de democracia, un concepto que se ha forjado, precisamente, en un proceso histórico.

El propio Tribunal Constitucional ha acudido en ocasiones al "constitucionalismo histórico" no ya para fundar sus Sentencias - algo obvio, ya que supondría una violación manifiesta del canon de constitucionalidad que impone el art. 28 LOTC- pero sí para proporcionar un cabal conocimiento de institutos constitucionales, ya sea por vía afirmativa o excluyente: así en relación con el sistema de investidura de los Presidentes (STC 5/1987, de 27 de enero, FJ $3^{\circ}$ ), los estados de crisis (STC 71/1994, de 3 de marzo, FJ 3), el derecho de petición (STC 242/1993, de 14 de julio, FJ 1º), los derechos forales (STC 94/1985, de 29 de julio, FJ $6^{\circ}$ ), los derechos fundamentales (STC 53/1985, de 11 de abril, FJ $4^{\circ}$ ), las causas de inelegibilidad e incompatibilidad de diputados y senadores (STC 72/1984, de 14 de junio, FJ $3^{\circ}$ ), la libertad sindical y de opinión de los funcionarios (STC 81/1983, de 10 de octubre, FJ $2^{\circ}$ ), el derecho a crear partidos políticos (STC 3/1981, de 2 de febrero, FJ $1^{\circ}$ ) o los colegios profesionales (STC 89/1989, de 11 de mayo, FJ 5 $5^{\circ}$. También en ocasiones se ha referido a Constituciones históricas concretas, como la de Cádiz ${ }^{22}$, sobre todo para remontarse a los precedentes de regulaciones actuales.

gano consultivo. Vid. Rubio Llorente, F., en Gómez Montoro, A.J., (edit.), La reforma del Estado autonómico. Jornadas de estudio sobre el Informe del Consejo de Estado, CEPC, Madrid, 2007, pág. 15.

21 Otro ejemplo claro es el relativo a las formas de gobierno: la diferencia entre parlamentarismo, asambleísmo o presidencialismo es muy difícil de explicar prescindiendo de antecedentes constitucionales.

22 Sólo por citar algunas sentencias: STC 133/2005, de 23 de mayo, FJ 6º STC 113/2004, de 12 de julio, FJ 2; STC 3/2003, de 16 de enero, FJ 3०; STC 187/1999, de 25 de octubre, FJ 5०; STC 126/1997, de 3 de julio, FJ $7^{\circ}$ A; STC 176/1995, de 11 de diciembre, FJ 2; ATC 259/1993, de 20 de julio, FJ 1; STC 225/1992, de 14 de diciembre, FJ 1; STC 36/1981, de 12 de noviembre, FJ $1^{\circ}$ ). 
ABSTRACT. Studies on Spanish Constitutional History have reached an important development. However, it is not clear yet which is the most suitable metbodology to study Constitutional History. The main trouble to find a consensus about the methodology may be connected with the lack of a clear definition of the Constitutional History object, that in fact includes the study of historical Constitutions but also the analysis of the constitutionalism doctrine. Once the Constitutional History object has been clarified, this article pretends to remark the benefits that Constitutional History can get from constitutionalist scholars and, on the other side, the benefits that constitutionalists can obtain by studying their country. 